\title{
Application of multiple biological indices for river health assessment in northeastern China
}

\author{
Xiaodong $\mathrm{Qu}{ }^{1,2}$, Haiping Zhang ${ }^{2}$, Min Zhang ${ }^{2}$, Meng Liu ${ }^{2}$, Yang $\mathrm{Yu}^{2}$, Ying Xie ${ }^{2}$ \\ and Wenqi Peng ${ }^{1,2 *}$ \\ ${ }^{1}$ State Key Laboratory of Simulation and Regulation of Water Cycle in River Basin, China Institute of Water Resources and \\ Hydropower Research, Beijing 100038, China \\ 2 Department of Water Environment, China Institute of Water Resources and Hydropower Research, Beijing 100038, China
}

Received 26 January 2015; Accepted 28 January 2016

\begin{abstract}
Bioassessment has become a hot topic and could provide important information for river management and restoration. In this study, we developed multiple biological indices using three groups of aquatic organisms - benthic algae, macroinvertebrates and fish - for river health assessment. The main steps for development of multiple biological indices were selection of sensitive indices, optimization of core indices, setting target and critical values for core indices, and calculation of final scores of health condition. In order to evaluate the 19 candidate indices, disturbance gradients were constructed for water contamination, sediment contamination and land use change using principal components analysis. Thirteen indices showed significant and relatively high coefficients of determination with the disturbance gradients using multiple regression analysis $(P<0.05)$. Six indices - two indices each for benthic algae, macroinvertebrates and fish were finally selected as the core indices using correlation analyses. River health condition scores were assigned to five categories: critical, poor, fair, good and excellent. One site was classified as critical and $10.5 \%$ of sites were in poor condition. Meanwhile, $45.6 \%$ of the sampling sites were classified as fair and $42.1 \%$ were either good or excellent. Regression analysis between the final scores and disturbance gradients confirmed the usefulness of multiple biological indices as a confident bioassessment method. Thus, we highly recommend using multiple biological indices to assess river health that will inform river management and restoration strategies.
\end{abstract}

Key words: River health assessment / multiple biological indices / bioassessment / target and critical values

\section{Introduction}

Rivers and streams are valuable ecosystems that sustain the biodiversity of freshwater organisms and provide different goods and services for human beings (Karr and Chu, 1999; Millennium Ecosystem Assessment, 2005; Arthington et al., 2006). River health assessment using biological indices continues to be widely used since its initial development several decades ago (Hynes, 1960; Norris and Hawkins, 2000). Benthic algae, macroinvertebrates and fish are commonly used in bioassessment due to their importance for riverine ecosystems, representation of river health condition and convenience for sampling, identification and calculation of biological indices (Rosenberg and Resh, 1993; Chessman and Royal, 2004; Kennard et al., 2006).

\footnotetext{
*Corresponding author: pwq@iwhr. com
}

By integrating different kinds of biological indices, multimetric approaches of bioassessment have been shown to be comprehensive methods reflecting different kinds of human disturbances, and have therefore been applied widely for freshwater ecosystems (Karr, 1981; Hawkins, 2006). Different taxonomic groups respond differently to environmental stressors (Hering et al., 2006). Biological indices of macroinvertebrates usually show higher sensitivities for organic pollution (Álvarez-Cabria et al., 2011) and heavy metal contamination (Clements et al., 2000; Qu et al., 2010) than fish and benthic algae. The close relationship between in-stream heterogeneity of substrate and macroinvertebrate biodiversity make macroinvertebrate indices more suitable to reflect in-stream habitat disturbances, such as dredging, sedimentation, and sand and gravel extraction (Bae et al., 2011; Zheng et al., 2011). Benthic diatoms usually show higher sensitivity and stronger response at low levels of nutrient 
concentrations, often before the effects on fish and macroinvertebrate communities are observed (Allan and Castillo, 2007). Thus, benthic algae may be a better indicator of eutrophication than other organisms (Stevenson and Pan, 1999). Fish usually show higher sensitivity to hydraulic alteration in rivers and as such are suitable indicators of flow regulation (Arthington et al., 2006). Dam construction usually causes severe degradation of fish communities; however, the effects may not be clearly identified in the short-term by benthic algae (Wu et al., 2009).

In the past, most approaches often used one kind of aquatic organism to assess river health, based on expert opinion and budget limitations (Barbour et al., 1999; Boulton, 1999). In recent years, improved understanding of the relationships among the physical, chemical and biological aspects have led to comprehensive assessments that use a wider range of aquatic organisms and ecosystem processes (Flinders et al., 2008; Meng et al., 2009; Bunn et al., 2010; Bae et al., 2011, 2014). Considering the long-term history of development and severe stresses to Chinese rivers, multiple biological indices have been applied by the National River and Lake Health Program (NRHLP) for river management and restoration. The NRHLP aims to evaluate the current condition of rivers and lakes and was initiated by the Ministry of Water Resources of China. It developed a comprehensive river health assessment based on five components of biological, physical, chemical, hydrological integrity and ecological services. Multiple indices of benthic algae, macroinvertebrate and fish were recommended to assess river health for the biological integrity component of the NRHLP.

In this study, we describe how we selected the suitable biological indices by deriving abiotic stressor gradients to determine target and critical values for biological integrity. The first objective was suitable indices selection, those which responded to human disturbances and environmental stressors. The second objective was health score calculation that combined several indices from different categories of aquatic organisms.

\section{Materials and methods}

\section{Study area}

The Taizi River is located in southeastern Liaoning Province, China, bordering the Yellow Sea and the Bohai Gulf to the south. The river is $413 \mathrm{~km}$ long with a watershed area of $1.39 \times 10^{4} \mathrm{~km}^{2}$. The research area is located at middle and high latitudes within the temperate continental monsoon climate zone. The Taizi River supplies the main water resources for domestic, industrial and irrigation purposes for the surrounding cities and farmland in the watershed. Industrial development and urbanization have caused severe water contamination in the Taizi River during the past few decades.

\section{Sample collection}

Benthic algae, macroinvertebrates and fish were collected from 57 sampling sites in the Taizi River from August to September 2014 (Fig. 1). The sampling region was classified into three stream types of highland, midland and lowland based on patterns of altitude, precipitation and macroinvertebrate communities (Leigh et al., 2012; Kong et al., 2013). Among the 57 sampling sites, 23 sites were located in the highland, 20 sites were located in the midland and 14 sites were located in the lowland (Fig. 1). A 300-m section of stream channel was selected to sample the aquatic organisms at each site.

Fish were sampled by electrofishing for $30 \mathrm{~min}$. Due to the high mobility of fish, the upstream and downstream sections of the sampling reach were blocked with a gill net $\left(1 \times 1 \mathrm{~cm}^{2}\right.$ net size $)$ during the sampling period. All collected fish were identified, enumerated and weighed in situ. Identifications were to the species level according to Zhang (1995) and Xie (2007). Rare and/or unknown species were preserved with $4 \%$ formalin for identification in the laboratory. The other individuals were returned to the stream where they were captured. No fish were captured at one sampling site.

Both diatoms and macroinvertebrates were sampled using quantitative methods. Nine stones (diameter $\sim 25 \mathrm{~cm}$ ) were randomly picked within the 300 -m sampling reach. A $3.5-\mathrm{cm}$ diameter PVC pipe, rubber corer and toothbrush were used to thoroughly scrub and rinse benthic algae from each stone. Each sample and rinsed water were combined together and preserved using a $4 \%$ formalin solution in a 50 -mL plastic bottle. In the laboratory, diatom slides were kept in a glass jar to oxidize the organic material with acid disposal. Within each diatom slide, a minimum of 300 valves were counted under high magnification oil emersion. The "soft" algae were identified directly using a $0.1-\mathrm{mL}$ counting chamber. Most of the benthic algae were identified to the species level using the classic manuals of $\mathrm{Hu}$ et al. (1980) and Zhu and Chen (2000).

Benthic macroinvertebrates were collected using a Surber net with three replicates $\left(30 \times 30 \mathrm{~cm}^{2}\right.$ and $500-\mu \mathrm{m}$ mesh size). The substrate was kicked or disturbed using a shovel into the net. The sample was then transferred from the net to a $10-\mathrm{L}$ plastic container. After rinsing all the samples through stainless steel frames with $40-\mathrm{mm}$ mesh, all the samples were put into a $500-\mathrm{mL}$ jar and preserved with $70 \%$ alcohol. In the laboratory, macroinvertebrates were identified to the lowest level, mainly to the genus level according to the manuals (Morse et al., 1994; Merritt and Cummins, 1996).

\section{Environmental parameters: land use, water quality and sediments}

The proportion of land use types at both watershed and riparian scales were used as the primary disturbance gradient to evaluate the sensitivity of biological indices. Three main types of land uses, including forest, farmland 


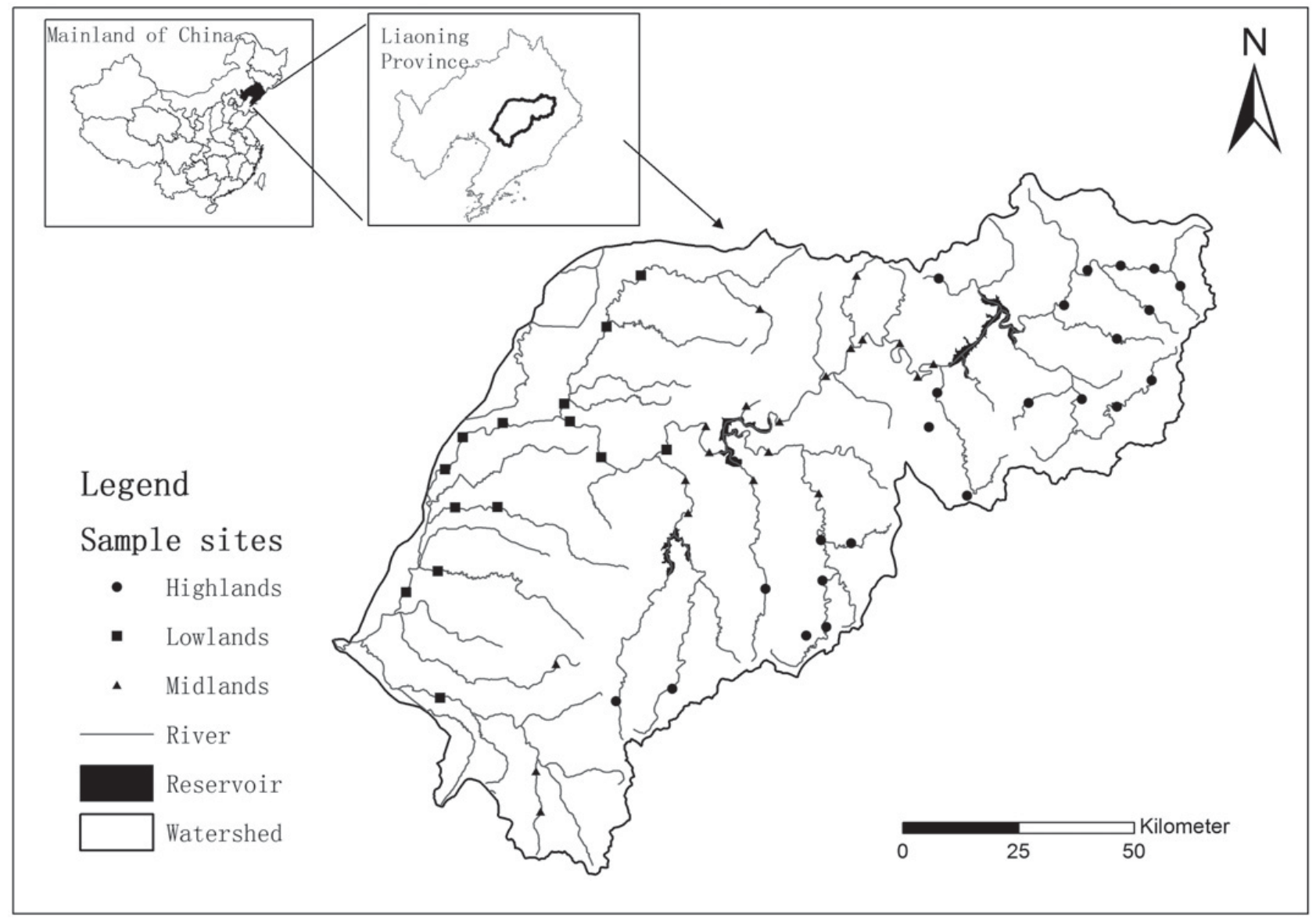

Fig. 1. Sampling site distribution with different symbols representing the three river type categories of highland, midland and lowland in the Taizi River basin.

and impervious areas of urban land, were extracted from 2010 Landsat-5 TM and Landsat-7 ETM + images using ArcGIS 9.0 Desktop GIS software. The proportion of each land use within the catchment upstream from each site was calculated. Meanwhile, the proportion of each land use within a riparian zone $10-\mathrm{km}$ long and $1-\mathrm{km}$ wide on either side of the riverbank upstream of the sampling site was also calculated.

At each sampling site, dissolved oxygen (DO), conductivity, total dissolved solids (TDS) and $\mathrm{pH}$ were measured using an multiparameter instrument (HQ40, HACH company, USA) in situ. In addition, stream water and sediments were sampled at each study site. The water and sediment samples were stored over ice and moved to the laboratory within 2 days. In the laboratory, concentrations of total suspended solid, alkalinity, 5-day biological oxygen demands $\left(\mathrm{BOD}_{5}\right)$, chemical oxygen demand (COD), permanganate, ammonia nitrogen, nitrite, nitrate, total nitrogen, active phosphate and total phosphorus were measured according to the Chinese Standard Methods for Examination of Water and Wastewater (MEP, 2009). Total dissolved carbon and dissolved organic carbon of sediment were also measured according to Chinese Standard Methods for Sediment (ISO-10694-1995). Sediment samples were further freeze-dried, powdered and sieved through a $100-\mu \mathrm{m}$ mesh nylon sieve. Then $0.1 \mathrm{~g}$ of sediment subsample was collected randomly and digested in Teflon vessels with $10 \mathrm{~mL} \mathrm{HNO}_{3}$ in a microwave oven (MARSX-press, CEM company, USA). Each sample solution was adjusted to $50 \mathrm{~mL}$ with twice-deionized water and filtered through a $0.45-\mu \mathrm{m}$ membrane for further analysis. The sediment extracts were measured for iron (Fe), manganese $(\mathrm{Mn})$, zinc $(\mathrm{Zn})$, copper $(\mathrm{Cu})$, cadmium $(\mathrm{Cd})$, chromium $(\mathrm{Cr})$, nickel $(\mathrm{Ni})$ and lead $(\mathrm{Pb})$ using inductively coupled plasma-mass spectrometry (Agilent $7500 \mathrm{CX}$ ).

\section{Biological indices of aquatic organisms}

Eight benthic algae indices, four fish indices and seven macroinvertebrate indices were selected as the main biological indices. Biological indices were mainly selected based on community composition, biodiversity, sensitivity and tolerance. Total abundance, taxa richness and Shannon-Wiener $(\mathrm{H})$ biodiversity were used for algae, fish and macroinvertebrates, and Berger-Parker (BP) dominance (Magurran, 2004) was selected for fish and macroinvertebrates. Five diatom-based indices were selected, including Biological Diatom Index (IBD), Schiefele and Schreiner's Index (SHE), Specific Pollution Sensitivity Index (IPS), Descy Index (DES), and Rott Saprobic Index (ROTT). The diatom-based indices (Table 1) were 
Table 1. The average, standard division and range of stream water, sediments, land uses and biological indicators in the sampling period of Taizi River.

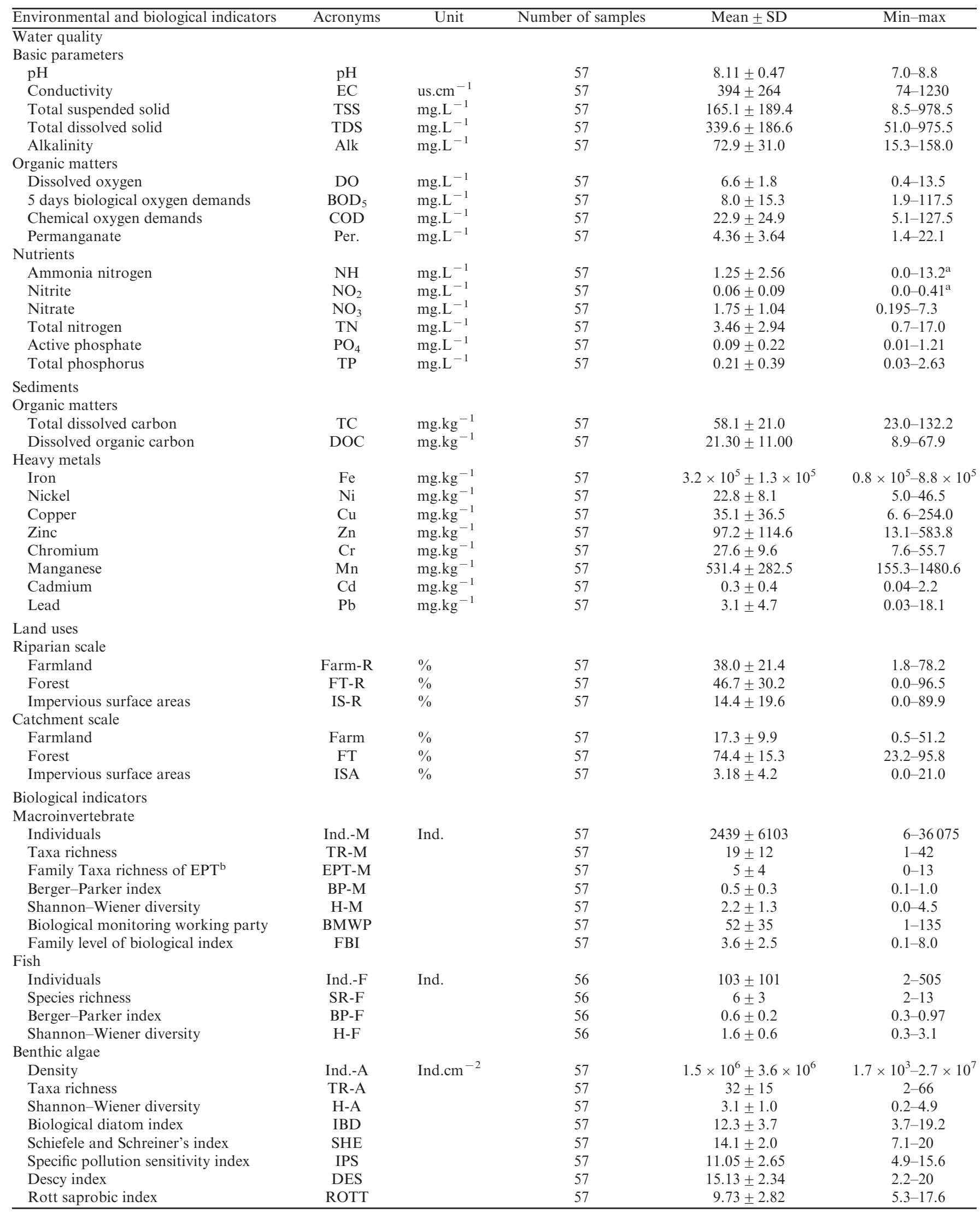

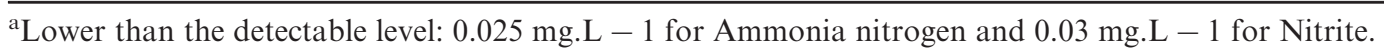

${ }^{b}$ EPT: Ephemeroptera, Plecoptera and Trichoptera. 
calculated using OMNIDIA software (Version 8.0, Lecointe et al., 2003). The other three macroinvertebrate indices were family-level taxa richness of Ephemeroptera, Plecoptera and Trichoptera (EPT; Barbour et al., 1999), Biological Monitoring Working Party (BMWP; Hellawell, 1986), and family-level biological index (FBI; Hilsenhoff, 1988). Biological indices were selected due to their wide use in biological assessments and simple calculation for river health. All indices are summarized in Table 1.

\section{Data analysis}

Associations between environmental factors and biological indices were analyzed separately using Spearman rank correlation analysis. This non-parametric method identifies the most significant correlations (Table 2). Before the analysis, the distributions of data were checked to identify outliers. Principal component analysis (PCA) was performed to detect principal patterns of variation within the environmental variables. Before PCA, the environmental factors with high partial correlation coefficients $(r>0.75)$ were eliminated. Then the environmental data matrix of the remaining variables was re-analyzed by PCA to reduce the dimensionality of the original data into a few easily interpretable principal components. After generalization by PCA procedures, the first four PC axes representing the general environmental and stressor gradients were used to evaluate sensitivities of biological indices using multiple linear regression analysis. A forward stepwise procedure of linear regression analysis was followed to find the models that gave the best fit. Residuals were also checked to ensure model assumptions were not violated and data were transformed as necessary. Finally, the sensitivity and suitability of the generalized river health scores to environmental gradients were evaluated using linear regression analysis. All the data analyses were conducted using STATISTICA 7.0 or Microsoft Excel 2013.

\section{Integrated river health index}

For the purpose of constructing an integrated river health index, core indices showed relatively higher sensitivities to disturbance gradients, better representations of the health condition and lower intra-correlations. These core indices were recommended according to regression analysis using approximate proportion of variation $\left(R^{2}\right.$ value $)$ and significance $(P<0.05)$. Intra-correlation among different biological indices was also considered for core indices selection. When two indices had significant $(P<0.05)$ and relatively high correlation coefficients $(r>0.75)$, one of the indices was eliminated from further analysis. Finally, the modeled stressor gradients and biological indices were verified such that they responded in the expected direction. In general, models were rejected if predictors were not significantly correlated with the stressor gradients $(P>0.05)$, or if modeled responses were in the opposite direction to that expected.

The core indices were then standardized using the target and critical values. Target values represent good river health under the best attainable condition (BAC), and critical values represent the unacceptable or degraded river health condition in this study. These target and critical values were mainly cited from published papers or referred from similar research in the same region. All core indices were standardized from 0 to 1 using the target and critical values, where 1 represents the $\mathrm{BAC}$ and 0 represents the unacceptable condition. Then the scores were averaged within each aquatic fauna category. The generalized river health score for each sampling site was calculated by averaging the scores across aquatic fauna categories. Thus, the final score ranging from 0 to 1 was used to represent the river health condition.

Five levels of health condition were established to represent river health, including critical, poor, fair, good and excellent. The "critical" health condition ranged from 0 to 0.2 representing severe impact from human activities with high homogeneity of aquatic organisms or even no aquatic organisms. The "poor" health condition ranged from 0.2 to 0.4 with severe to moderate human disturbances. The aquatic community was dominated by taxa tolerant of poor water quality. The "fair" health condition ranged from 0.4 to 0.6 and had moderate human disturbances. The aquatic community had several dominant, moderately tolerant taxa. The "good" health condition ranged from 0.6 to 0.8 , which was indicative of a low level of human disturbance. These sites had relatively high taxa richness and abundance dominated by intolerant or sensitive taxa. The "excellent" health condition ranged from 0.8 to 1.0 representing the least human disturbance, where the aquatic community was dominated by diverse and sensitive taxa and the indicator species for habitat and water quality were present. Five levels of health condition are commonly used in river health assessment for the US Environmental Protection Agency (Barbour et al., 1999), EU Water Framework Directive (Hering et al., 2010) and other countries (Park et al., 2007; Bunn et al., 2010).

\section{Results}

\section{Environmental characteristics}

All water quality factors except $\mathrm{pH}$ showed a wide range of values from the least polluted condition to high organic pollution, or nutrient enrichment (Table 1). The $\mathrm{pH}$ values reflected low acidification according to the average value of 8.11 and low standard deviation. Total suspended solids (TSS) and TDS had relatively high average and standard deviation values, potentially due to sand extraction in some areas of the stream channel, even though the sampling team avoided collecting samples after rain. Extremely low DO values (e.g., $0.4 \mathrm{mg} . \mathrm{L}^{-1}$ ) and relatively high $\mathrm{BOD}_{5}$ and $\mathrm{COD}$ values (e.g., $>100 \mathrm{mg} \cdot \mathrm{L}^{-1}$ ) were observed, potentially indicating high 


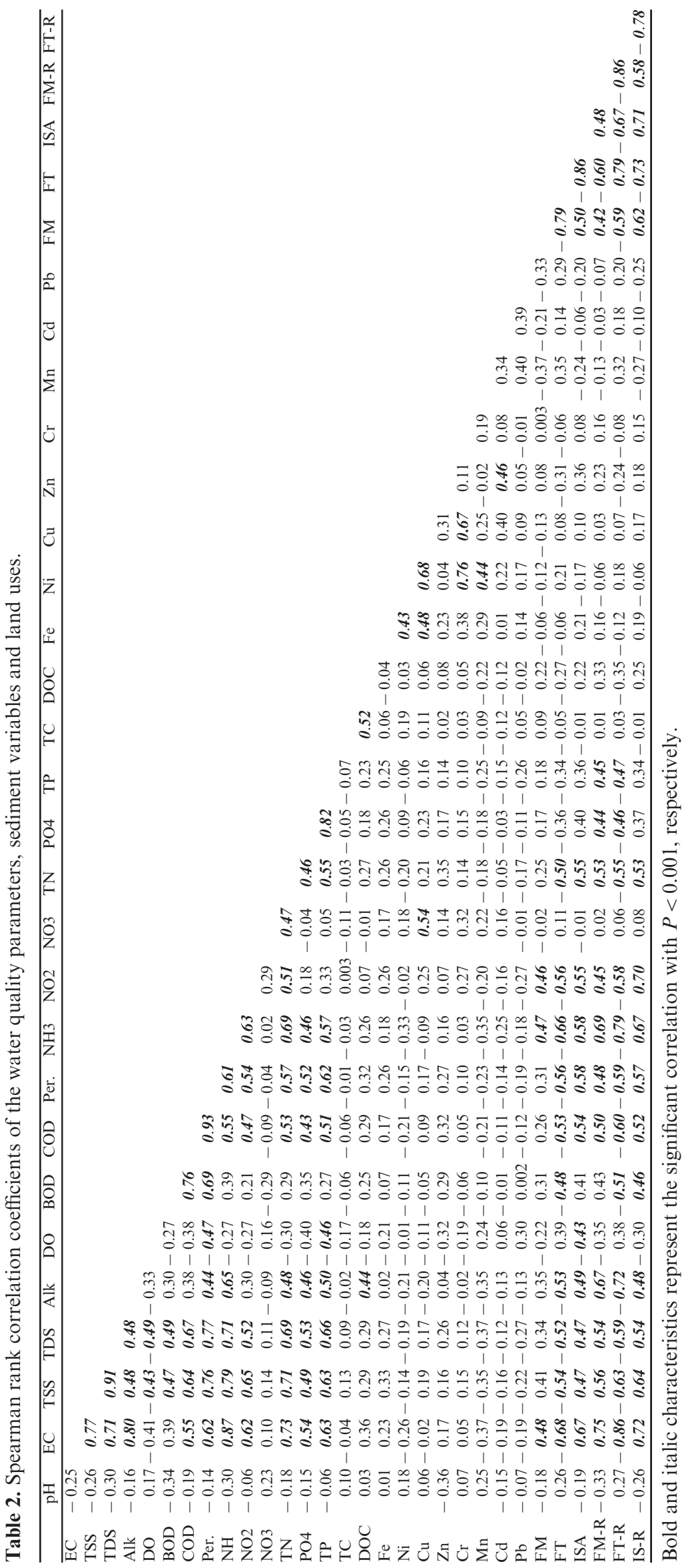



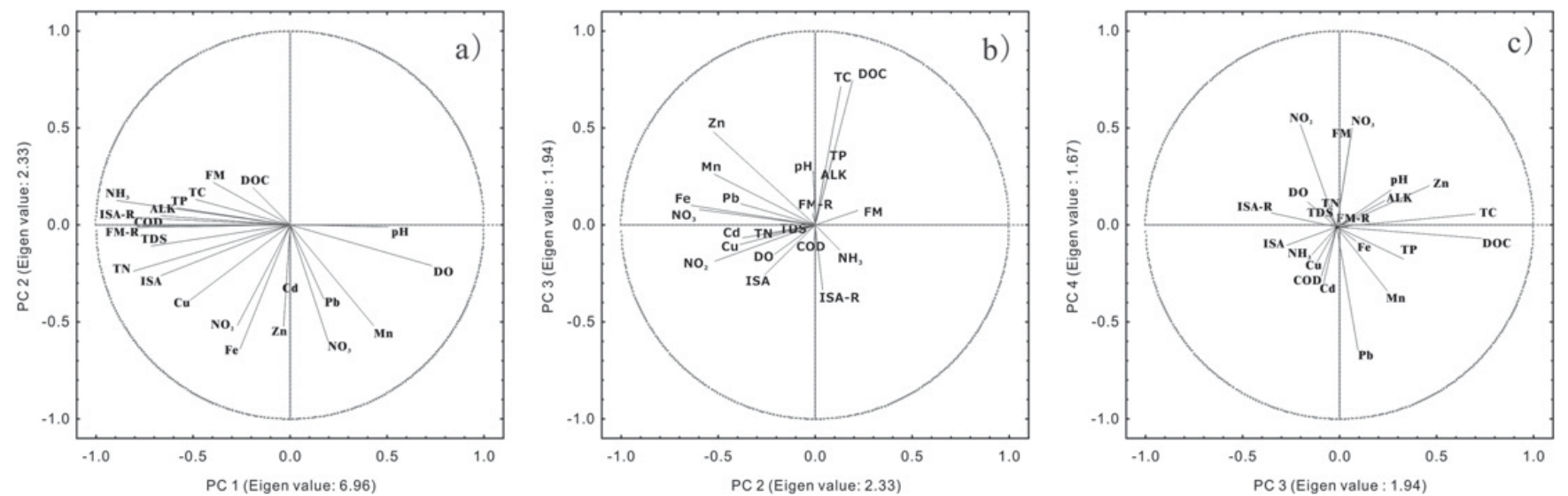

Fig. 2. Principal component analysis (PCA) ordination plots for 22 water quality parameters at the 57 sites sampled in the Taizi River basin. (a) PC $1 \times$ PC 2; (b) PC $2 \times$ PC 3; (c) PC $3 \times$ PC 4 .

organic pollution. Nitrogen enrichment was significant in the Taizi River. The average values of total nitrogen were relatively higher than other nutrients according to the Chinese Environmental Quality Standard for Surface Water (Table 1).

The measurement of heavy metals in the sediment showed that iron was the predominant metal in the surface sediment with an average concentration of $3.2 \times 10^{5} \mathrm{mg} \cdot \mathrm{kg}^{-1}$. Manganese had an average value of $531.4 \mathrm{mg} . \mathrm{kg}^{-1}$, which was relatively higher than concentrations of the other metals, which were usually lower than $100 \mathrm{mg} \cdot \mathrm{kg}^{-1}$. Compared with the background levels of heavy metals found in regional soils in Liaoning Province, cadmium, copper and zinc were considered the main pollutants in surface sediments of Taizi River (Table 1).

The dominant land use type was forest at both catchment and riparian scales (Table 1). However, land use for several sampling sites was dominated by farmland, considering the maximum value was $78.2 \%$ at the watershed scale and $51.2 \%$ at the riparian scale. Impervious surface areas were high at some sites, with around $89.8 \%$ at the watershed scale. Generally, impervious surface areas were relatively low: around $14.4 \%$ at the watershed scale and $3.18 \%$ at the riparian scale (Table 1 ).

\section{Biological indices}

The high variation in total abundance of macroinvertebrate, fish and algae showed that samples could represent different environmental and habitat conditions and levels of human disturbance in the research area (Table 1). Considering that land use was dominated by forest, the research area showed relatively low family richness of EPT taxa, with five families on average and a maximum of 13 families. Meanwhile, the taxa richness of fish also showed relatively low values, with six species on average and a maximum of 13 species. According to similar research in the Taizi River, the other biological indices encompassed the range between least and most polluted condition (Table 1).

\section{Disturbance gradients}

Spearman rank correlation analysis showed broad correlations among the environmental factors (Table 2). Five water quality factors, including conductivity, TDS, $\mathrm{BOD}_{5}$, permanganate and active phosphate, were eliminated from further analysis according to the high correlation coefficients $(r=0.75-0.91)$. Nickel, chromium and copper showed significant correlations $(r=0.67-0.76)$ for the heavy metal concentrations in the sediment. Both chromium and nickel were eliminated from further analysis. All types of land use showed wide and significant correlations $(P<0.001)$. The same types of land use also showed intra-correlations at both catchment and riparian scales. Considering the land use types and coefficient values, forest was eliminated from analysis at both catchment and riparian scales (Table 2).

Finally, 22 environmental factors were used in the PCA (Fig. 2). The first four axes were constructed to explain the dominant disturbance gradients on the basis of the decline in eigenvalues in the PCA. Four axes accounted for $58.6 \%$ of the total variance, within which the first axis accounted for $31.6 \%$ (eigenvalue 6.96 ), the second accounted for $10.6 \%$ (eigenvalue 2.33; Fig. 2(a)), the third accounted for $8.8 \%$ (eigenvalue 1.94; Fig. 2(b)) and the fourth accounted for $7.6 \%$ (eigenvalue 1.67; Fig. 2(c)). The main explanatory parameters for the first PC axis were negatively correlated, including ammonia nitrogen, total nitrogen, TDS, COD, DO, farmland and impervious surface area at the riparian scale. The main explanatory parameter for the second PC axis was iron (Fig. 2(a)). Dissolved organic carbon and total dissolved carbon in the sediment explained the main variance in the positive direction for the third PC axis (Fig. 2(b)). Lead explained most of the variance in the negative direction for the fourth PC axis (Fig. 2(c)).

\section{Core indices}

Before selecting core indices, the intra-correlations of biological indices were analyzed using Spearman rank 
Table 3. Spearman rank correlation coefficients of biological indicators.

\begin{tabular}{|c|c|c|c|c|c|c|c|c|c|c|c|c|c|c|c|c|c|c|}
\hline & Ind.-M & TR-M & EPT-M & BP-M & H-M & BMWP & FBI & Ind.-F & SR-F & BP-F & H-F & Ind.-A & TR-A & H-A & IBD & SHE & IPS & $\overline{\mathrm{DES}}$ \\
\hline$\overline{\text { TR-M }}$ & 0.45 & & & & & & & & & & & & & & & & & \\
\hline ЕРT-M & 0.38 & 0.95 & & & & & & & & & & & & & & & & \\
\hline BP-M & 0.02 & -0.73 & -0.70 & & & & & & & & & & & & & & & \\
\hline H-M & 0.08 & 0.86 & 0.85 & -0.94 & & & & & & & & & & & & & & \\
\hline BMWP & 0.39 & 0.94 & 0.93 & -0.69 & 0.81 & & & & & & & & & & & & & \\
\hline FBI & 0.05 & -0.19 & -0.23 & 0.07 & -0.11 & -0.21 & & & & & & & & & & & & \\
\hline Ind.-F & 0.14 & 0.26 & 0.23 & -0.16 & 0.16 & 0.28 & -0.05 & & & & & & & & & & & \\
\hline R-F & 0.07 & 0.09 & 0.07 & 0.10 & -0.03 & 0.11 & -0.10 & 0.69 & & & & & & & & & & \\
\hline BP-F & 0.13 & 0.14 & 0.14 & -0.20 & 0.11 & 0.14 & 0.02 & 0.07 & -0.41 & & & & & & & & & \\
\hline $\mathrm{H}-\mathrm{F}$ & -0.14 & -0.15 & -0.14 & 0.23 & -0.15 & -0.12 & -0.01 & 0.24 & 0.76 & -0.73 & & & & & & & & \\
\hline Ind.-A & 0.31 & 0.22 & 0.20 & -0.03 & 0.06 & 0.22 & -0.34 & 0.18 & 0.25 & -0.19 & 0.13 & & & & & & & \\
\hline TR-A & 0.16 & 0.12 & 0.12 & 0.00 & 0.06 & 0.09 & -0.36 & 0.12 & 0.36 & -0.23 & 0.30 & 0.63 & & & & & & \\
\hline H-A & 0.10 & 0.09 & 0.12 & -0.03 & 0.08 & 0.09 & -0.23 & 0.04 & 0.36 & -0.15 & 0.33 & 0.08 & 0.63 & & & & & \\
\hline IBD & -0.20 & -0.44 & -0.38 & 0.28 & -0.38 & -0.47 & 0.08 & -0.14 & -0.17 & -0.08 & -0.04 & -0.13 & -0.22 & -0.12 & & & & \\
\hline SHE & -0.04 & -0.17 & -0.16 & 0.07 & -0.12 & -0.12 & 0.28 & -0.15 & -0.06 & -0.09 & 0.08 & 0.11 & 0.05 & -0.07 & -0.03 & & & \\
\hline IPS & -0.17 & -0.25 & -0.22 & 0.16 & -0.22 & -0.23 & -0.12 & -0.18 & -0.09 & -0.20 & 0.06 & 0.20 & 0.00 & -0.08 & 0.57 & 0.38 & & \\
\hline DES & 0.07 & 0.21 & 0.23 & -0.18 & 0.23 & 0.18 & 0.39 & -0.16 & -0.11 & -0.13 & 0.03 & -0.13 & -0.29 & -0.19 & 0.12 & 0.31 & 0.21 & \\
\hline ROTT & 0.19 & 0.24 & 0.26 & -0.20 & 0.18 & 0.24 & 0.04 & 0.11 & 0.06 & -0.12 & 0.13 & 0.08 & -0.15 & -0.07 & 0.09 & 0.25 & 0.07 & 0.30 \\
\hline
\end{tabular}

Bold and italic characteristics represent the significant and high correlations $(P<0.001$ and $|r|>0.75)$.

Table 4. Adjusted coefficients of determination $\left(R^{2}\right)$ from linear regressions used to analyze the response of biological indices to the multiple stressor gradients (PCA axis 1,2, 3 and 4).

\begin{tabular}{|c|c|c|c|c|}
\hline & Equation & Adjusted $R^{2}$ & $F$-value & $P$-value \\
\hline \multirow[t]{9}{*}{ PCA axis 1} & Ind.- $\mathrm{M}=-1301 \times$ PCA axis $1+2437$ & 0.29 & 23.69 & $<0.001$ \\
\hline & $\mathrm{TR}-\mathrm{M}=3.1 \times \mathrm{PCA}$ axis $1+19.9$ & 0.48 & 53.13 & $<0.001$ \\
\hline & $\mathrm{EPT}-\mathrm{M}=1.07 \times \mathrm{PCA}$ axis $1+5.33$ & 0.45 & 46.43 & $<0.001$ \\
\hline & $\mathrm{BP}-\mathrm{M}=0.073 \times \mathrm{PCA}$ axis $1+0.496$ & 0.50 & 56.10 & $<0.001$ \\
\hline & $\mathrm{H}-\mathrm{M}=0.35 \times \mathrm{PCA}$ axis $1+2.32$ & 0.55 & 70.80 & $<0.001$ \\
\hline & $\mathrm{BMWP}=9.4 \times \mathrm{PCA}$ axis $1+54.2$ & 0.47 & 50.14 & $<0.001$ \\
\hline & $\mathrm{FBI}=0.55 \times \mathrm{PCA}$ axis $1+3.32$ & 0.37 & 34.54 & $<0.001$ \\
\hline & $\mathrm{IBD}=-0.59 \times \mathrm{PCA}$ axis $1+12.42$ & 0.15 & 10.42 & 0.002 \\
\hline & $\mathrm{ROTT}=0.50 \times \mathrm{PCA}$ axis $1+9.76$ & 0.12 & 7.88 & 0.007 \\
\hline \multirow[t]{3}{*}{ PCA axis 2} & Ind. $-\mathrm{M}=1184 \times \mathrm{PCA}$ axis $2+2438$ & 0.07 & 4.93 & 0.031 \\
\hline & $\mathrm{BP}-\mathrm{F}=0.039 \times \mathrm{PCA}$ axis $2+0.556$ & 0.10 & 6.86 & 0.017 \\
\hline & $\mathrm{H}-\mathrm{F}=-0.12 \times \mathrm{PCA}$ axis $2+1.63$ & 0.08 & 5.39 & 0.032 \\
\hline \multirow[t]{2}{*}{ PCA axis 3} & $\mathrm{FBI}=-0.50 \times \mathrm{PCA}$ axis $3+3.32$ & 0.07 & 5.47 & 0.023 \\
\hline & $\mathrm{DES}=-0.35 \times \mathrm{PCA}$ axis $3+15.42$ & 0.08 & 5.30 & 0.025 \\
\hline \multirow[t]{3}{*}{ PCA axis 4} & $\mathrm{EPT}-\mathrm{M}=-1.01 \times \mathrm{PCA}$ axis $4+5.33$ & 0.08 & 5.89 & 0.018 \\
\hline & $\mathrm{TR}-\mathrm{A}=3.51 \times \mathrm{PCA}$ axis $4+33.44$ & 0.07 & 5.44 & 0.023 \\
\hline & $\mathrm{DES}=-0.35 \times \mathrm{PCA}$ axis $4+15.36$ & 0.09 & 5.90 & 0.019 \\
\hline
\end{tabular}

analysis (Table 3 ). The results showed that most macroinvertebrate indices were highly correlated $(r>0.75$, $P<0.001)$. The correlation coefficient between taxa richness and family richness of EPT taxa was highest $(r=0.95)$. Taxa richness, family richness of EPT taxa, Shannon-Wiener diversity index and BMWP scores were also correlated $(r=0.86-0.94)$. Shannon-Wiener diversity index was also highly negatively correlated with BergerParker index $(r=-0.94)$ and positively correlated with BMWP scores $(r=0.81)$. Two fish indices showed significant and high correlation: species richness and ShannonWiener diversity index $(r=0.76)$. None of the benthic algae indices showed high correlations in our study (Table 3). Considering the high correlations among BMWP scores, taxa richness and family richness of EPT taxa, one index was recommended as the core index. Between Berger-Parker index and Shannon-Wiener index of macroinvertebrates, and between species richness and Shannon-Wiener index of fish, one index for each group was recommended as the core index.

Four PC axes were used as disturbance gradients to evaluate the sensitivities of biological indices. Overall, 13 biological indices showed significant relationships with the first four PC axes (Table 4). The regression analyses revealed that biological indices of macroinvertebrates could be explained significantly by the first PC axis. The negative direction of the first PC axis represented the main water nutrient enrichment gradient and riparian land cover changes (Fig. 2(a)). Six macroinvertebrate indices showed positive relationships with the first PC axis, and macroinvertebrate abundance showed negative relationships with relatively high explanations (adjusted $\left.R^{2}=0.29-0.55\right)$. Two benthic diatom indices, biological diatom index and Rott saprobic index, also showed 
Table 5. Selected references values of core biological indices used for the river health assessment in the Taizi River.

\begin{tabular}{|c|c|c|c|c|c|c|}
\hline Categories & $\begin{array}{c}\text { Core } \\
\text { indicators }\end{array}$ & Regions & $\begin{array}{l}\text { Target } \\
\text { values }\end{array}$ & $\begin{array}{c}\text { Critical } \\
\text { values }\end{array}$ & Sites number & References \\
\hline \multirow[t]{2}{*}{ Algae } & ROTT & All & 20 & 0 & 57 & Lecointe et al. (2003); Qu et al. (2014) \\
\hline & DES & All & 20 & 0 & 57 & Lecointe et al. (2003); Qu et al. (2014) \\
\hline \multirow[t]{2}{*}{ Fish } & BP-F & All & 0.15 & 0.90 & 56 & Leigh et al. (2012); Zhang et al. (2013) \\
\hline & $\mathrm{H}-\mathrm{F}$ & All & 3 & 0 & 56 & Leigh et al. (2012); Wang et al. (2013) \\
\hline \multirow[t]{4}{*}{ Macroinvertebrate } & $\mathrm{H}-\mathrm{M}$ & All & 3 & 0 & 57 & Leigh et al. (2012); Qu et al. (2012) \\
\hline & EPT-M & Highland & 15 & 0 & 23 & Park et al. (2007); Leigh et al. (2012) \\
\hline & & Midland & 10 & 0 & 20 & Kerans and Karr (1994); Leigh et al. (2012) \\
\hline & & Lowland & 7 & 0 & 14 & Stribling et al. (1999); Leigh et al. (2012) \\
\hline
\end{tabular}

significant explanation with the first PC axis (adjusted $\left.R^{2}=0.12-0.15\right)$. The Descy index showed a significant linear model with the third and fourth PC axes, but at low levels of variance $\left(R^{2}=0.08-0.09, P<0.05\right)$. Two fish community indices, Berger-Parker index and ShannonWeiner biodiversity, were negatively correlated with the second PC axes. Taxa richness of benthic algae also showed significant correlation with the fourth PC axis (Table 4).

Based on the linear regression analysis, index representation and intra-correlations among different indices, six indices were used as core indices to construct the integrated river health assessment index. Core indices included two indices each of benthic diatoms, fish and macroinvertebrates (Table 5). The family richness of EPT taxa was finally selected as the core index due to its highly significant relationship with the main disturbance gradient, common application and easy calculation. Correspondingly, two highly correlated indices of BMWP scores and taxa richness of macroinvertebrates were eliminated. The Berger-Parker index of macroinvertebrates was eliminated due to its high correlation with the Shannon-Wiener biodiversity index of macroinvertebrates. Total abundance of macroinvertebrates was also eliminated since it is easily affected by sampling method and operator. Calculation of FBI mainly cited the tolerance values of macroinvertebrates from the USA, so FBI was not included in the core indices. Biological diatom index showed unpredicted correlations (Table 4) and was therefore not selected as a core index. Taxa richness of algae was eliminated due to the relatively low coefficients of determination. With further consideration of the broad applicability and accessibility of the target and critical values of each indicator, six indices were finally selected as core indices, including family richness of EPT taxa and Shannon-Wiener biodiversity index of macroinvertebrates, Descy index and Rott saprobic index of algae and Shannon-Wiener diversity and Berger-Parker index of fish (Table 5).

\section{Target and critical values}

The target and critical values of core indices were mainly referred from published papers or cited from similar research reports in the Liao River watershed (Table 5).
For the diatom-based indices, all the indices were standardized systematically from 0 to 20 in OMNIDIA 7.0. Thus, 20 was selected as the target value and 0 selected as the critical value (Table 5). For the Shannon-Wiener biodiversity index, 3 and 0 taxa were, respectively, selected as target and critical values according to locally published research of macroinvertebrate and fish biological integrity. Similarly, the Berger-Parker index was also cited from local research reports, and 15 and $90 \%$ were, respectively, used to represent the target and critical values of fish. The target values of EPT related with community composition and sensitive taxa of macroinvertebrates were different in different sampling regions. Target values were 15, 10 and 7 macroinvertebrate families in the highland, midland and lowland regions, respectively (Table 5).

\section{Calculation and evaluation of the integrated biological index}

Based on the target and critical values, each index was standardized and averaged to produce a final integrated biological index score at each sampling site. The results showed that $40.4 \%$ were in good condition, $45.6 \%$ were in fair condition and $10.5 \%$ were in poor condition. Only one site was classified either critical or excellent river health condition (Fig. 3). Among those sites, excellent and good river health conditions were mainly located in the highlands. Sampling sites from the midlands showed fair and good river health condition. Except one site from the upstream region, all of the sampling sites with critical and poor river health were restricted to the lowland region (Fig. 3).

Coefficients of determination for multiple linear regression correlations between the final river health score and the 11 environmental parameters that predominantly contributed to the construction of the first four PC axes (Fig. 2) were used to evaluate the sensitivity and stability of the integrated biological index (Fig. 4). As expected, the results showed that the final score was explained significantly by the first PC axis (Fig. $4, R^{2}=41.1, P<0.001$ ). The final score was also useful to predict nitrogen enrichment $\left(R^{2}=16.9-20.9, P<0.001\right)$ and organic pollution $\left(R^{2}=13.9, P<0.001\right)$. More importantly, the integrated biological index reflected the land use changes of agricultural development and urbanization within a $10-\mathrm{km}$ 


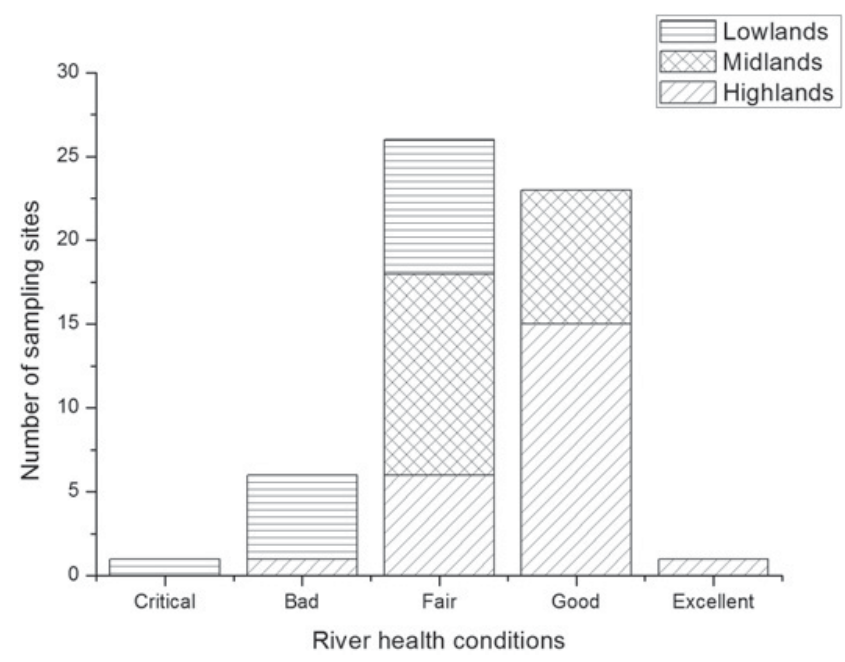

Fig. 3. River health assessment within the three categories of river types in the Taizi River.

riparian buffer $\left(R^{2}=13.1-18.5, \quad P<0.001\right)$. The final scores were not suitable for sediment heavy metal contaminations. Both $\mathrm{Fe}$ and $\mathrm{Pb}$ did not show significant regression correlations. It may be useful to reflect the organic pollution of sediments, although with relatively low explanation with total dissolved carbon (Fig. 4).

\section{Discussion}

\section{Usefulness of multiple biological indices}

The Taizi River is one example of a river that widely suffers from different kinds of human disturbances in the Liao River basin (Zhang et al., 2009). The PCA results reflected that the first four axes explained the main variation of human disturbances. The negative direction of the first PC axis integrated the dominant disturbances from water quality parameters of organic pollution, nutrient enrichment in water and sediments and land cover changes. The disturbance level increased gradually from highland (upstream reaches) to lowland (downstream reaches).

It is apparent that different categories of aquatic organisms reveal multiple human stressors at different spatial and temporal scales (Boulton, 1999). Our research confirmed that different biological indices showed varied sensitivity to the disturbance types (Table 4). The regression analyses revealed that macroinvertebrate indices showed broadly significant responses to a general environmental gradient in our study. The high sensitivity to different kinds of human disturbances has made macroinvertebrate indices as one of the most widely used indicators of river health (Metcalfe, 1989; Cairns and Pratt, 1993; Hering et al., 2004; Dolédec and Statzner, 2010). Diatom-based indices were mainly developed based on tolerance to organic pollution and eutrophication (Stevenson and Pan, 2004), and have proven to be useful indices to reflect river contamination in the same watershed (Qu et al., 2014). However, these indices did not show similar trends over different sampling periods. It is highly recommended that the suitability and applicability of diatom-based indices be evaluated over different seasons.

Considering the high mobility of fish between impacted and non-impacted areas, the evaluation and selection of fish indices may be difficult. Biodiversity indices of fish showed stronger responses to the second PC axis even with relatively low coefficients of determination (Table 3 ). Considering that the Taizi River suffers from severe industrial pollution, the concentration of heavy metals in the sediment may reflect the long-term history of heavy metal contamination. Thus, the fish community diversity indices would be more accurate to reflect the relatively long-term disturbances at the watershed scale. The sensitivity of fish indices was relatively low to identify the nutrient enrichment and organic pollution or land use changes in riparian areas in our study. Our study also did not identify correlations between sediments and macroinvertebrates, despite their sensitivity to sedimentation (Prygiel et al., 1999; De Lange et al., 2004; Rabeni et al., 2005) and low levels of heavy metal contamination (Clements et al., 2000; Qu et al., 2010).

The most suitable indices varied according to the levels of contamination or disturbances, across different watersheds, and between different sampling seasons. In our study, we found that macroinvertebrate indices were widely significant with the dominant stressor gradients of habitat disturbances and water contamination, as previously identified by Plafkin et al. (1989). In contrast, Hering et al. (2006) found that macrophytes and fish communities showed stronger responses to general degradation gradients in European bioassessment programs. Thus, multiple indices may be necessary to reflect multiple human disturbances, although advantages (and disadvantages) overlap among the three groups (Resh, 2008) and different characteristics of each aquatic fauna group can be matched to serve the specific study objectives (Bae et al., 2014). Meanwhile, it is important to select integrated biological indices to evaluate the advantages and disadvantages for restoration programs and also provide for the protection of river biological integrity with better management (Hering et al., 2010).

\section{Target and critical values}

It is necessary to define the target and critical values for the purpose of assessing river health condition based on the expected undisturbed or natural condition. However, the difficulty of defining the undisturbed or natural condition has encouraged relevant research and discussions (Karr, 1999; Hawkins et al., 2010). Due to long-term human activities and climate changes, it would be hard to select the totally "undisturbed" natural condition. For the biological integrity assessment, human activities and water quality in the upstream regions of the 

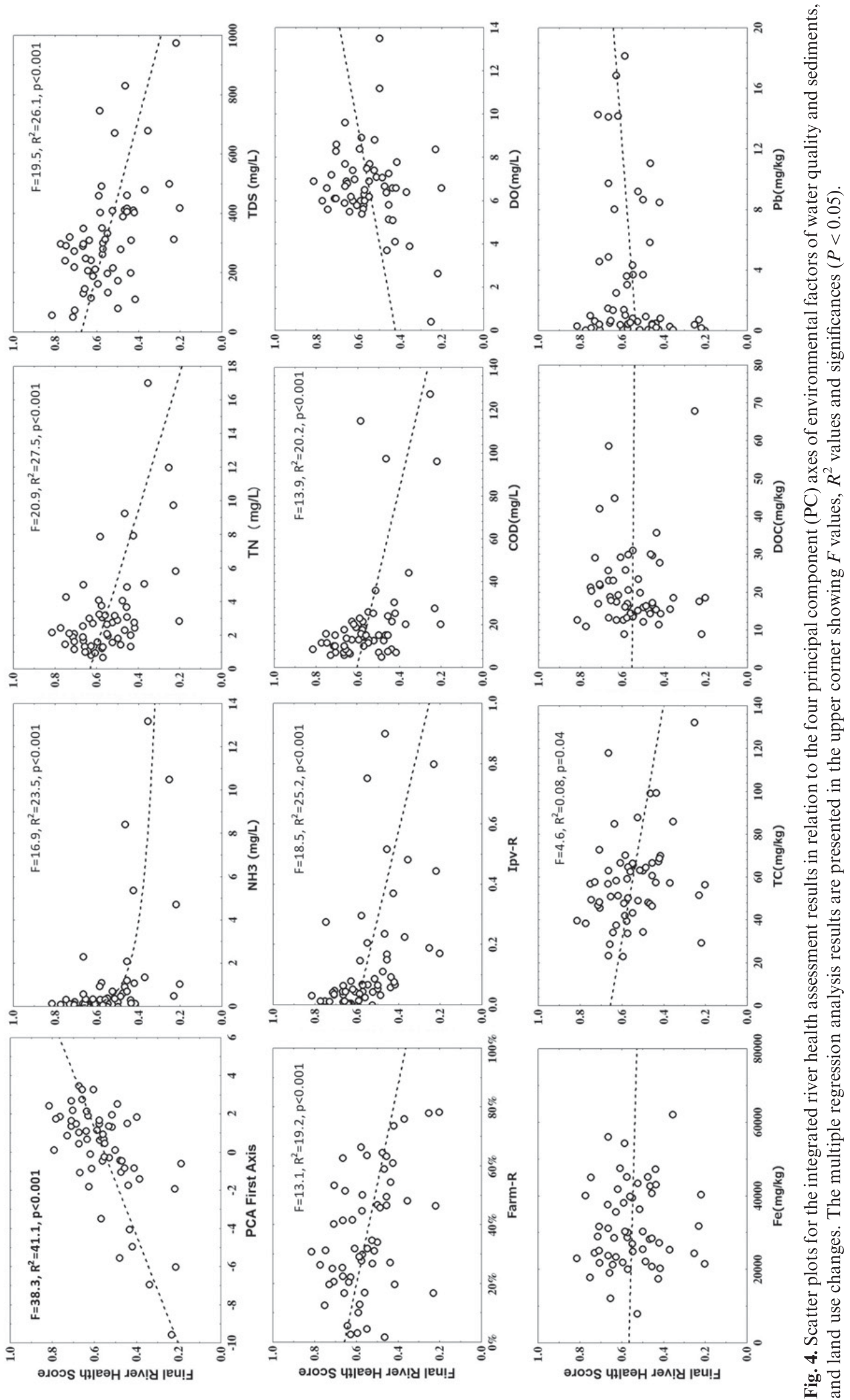

$\exists$
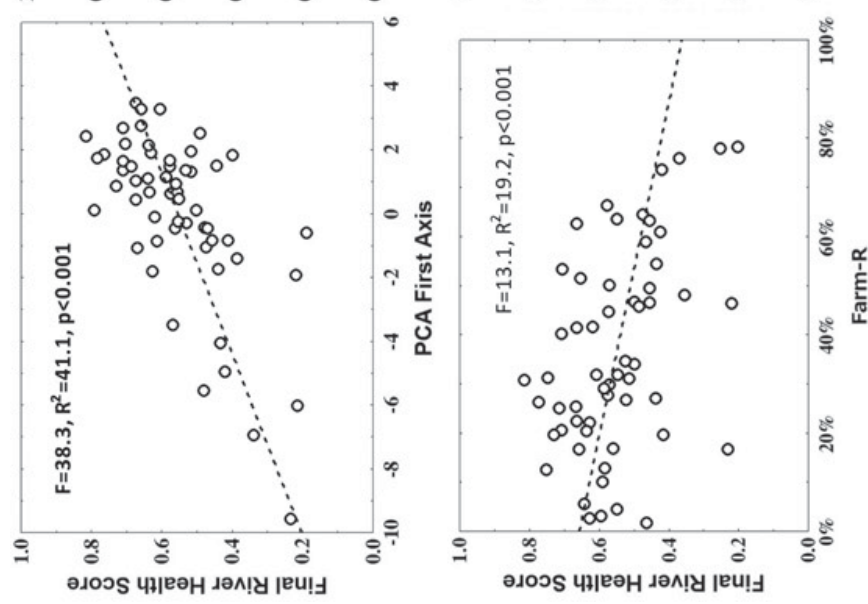
sampling region were the main standards (Reynoldson et al., 1997; Barbour et al., 1999). According to the EU Water Framework Directive, the reference condition does not necessarily refer to a totally undisturbed condition, although this causes new problems about how to compare the assessment results among different kinds of water bodies (Hering et al., 2010).

Stoddard et al. (2006) defined four different types of reference condition for streams: BAC, historical condition, minimally disturbed condition and least disturbed condition. Considering the long-term development history for most Chinese rivers, selecting the BAC as the reference condition would be appropriate and reasonable. Our results also confirmed that selecting sampling sites from the low level of human pressure to serve as the reference condition would be appropriate in the Taizi River. Expert opinions, the national water quality standards, and relevant literature were also useful resources used in our research (Kerans and Karr, 1994; Stribling et al., 1999; Lecointe et al., 2003; Park et al., 2007; Geng et al., 2012; Leigh et al., 2012; Wang et al., 2013; Zhang et al., 2013; Qu et al., 2014).

\section{Importance of stream classification}

Stream classification is crucial for river health bioassessment. Firstly, river classification is necessary for setting appropriate reference conditions, and ensures that comparisons are only made between comparable river systems (Bunn et al., 2010). In our study, stream types were classified into highland, midland and lowland based on natural environmental parameters (Kong et al., 2013). Secondly, the composition and function of aquatic organisms usually varies significantly from the headwaters to river mouth, as predicted by the river continuum concept (Vannote et al., 1980). Considering the high spatial patchiness of aquatic organism species composition, it is suitable to establish reference values according to the freshwater ecoregions (Abell et al., 2000). In this study, variations of aquatic organism communities within different river types were also considered (Qu et al., 2013; Wang et al., 2013; Yin et al., 2013). Thirdly, it is also suitable to select river health indicators according to the different stream types. Similar stressors may cause different responses to biological indices among different stream types within the same ecoregion. Leigh et al. (2012) already identified that hydrological alteration had different effects on the macroinvertebrate structural and functional attributes between dry lands and tropical streams in Australia. Finally, the river protection and management targets should be adjusted according to the river development and disturbances. Downstream reaches usually have a relatively higher level of development and disturbances than upstream reaches. Similar trends were also identified with relatively good river health condition at highland sampling sites and relatively fair river health condition in the lowland sampling sites (Fig. 3).

\section{Challenges of multiple biological indices}

Limited budgets and difficult identification for different categories of aquatic fauna are challenges for the application of multiple biological indices. Selection of indices that could be quickly calculated as rapid bioassessment indicators increases the applicability of multiple indicators in the river health assessment. If these indices could be calculated in situ, this may be even more convenient than the traditional methods. The limited number of sampling sites makes it difficult to draw robust conclusions. In our study, only 57 sites were sampled across three different river types. Several diatom-based indices already showed different trends compared with previous research in the same river during different sampling seasons (Qu et al., 2014). Long-term data records and more intensive sampling efforts may be required to provide more stable predictions and confident conclusions (Bae et al., 2011, 2014), especially for fish communities (Kennard et al., 2006). Selecting suitable target and critical values are a particular challenge when implementing a river health project for the first time, especially for those rivers without previous research. Further evaluation using a long-term larger data set and different rivers will contribute to filling this knowledge gap.

\section{Conclusions}

It is important to evaluate river health condition using a reliable and stable assessment method for better river management and restoration. In this study, multiple biological indices were developed for the Chinese NRHLP by integrating indices of benthic algae, macroinvertebrates and fish. The sensitive evaluation confirmed its usefulness in the river health assessment, especially for those rivers suffering long-term watershed development. Meanwhile, selection of sensitive indices according to their responses to general disturbance gradients and establishment of target and critical values based on references and expert opinions were realistic for a highly developed watershed. It was also appropriate to establish different target values for indices that were highly correlated with longitudinal community succession of macroinvertebrates from upstream to downstream. For example, different target values of family taxa richness of EPT were used in different regions of Taizi River in this study. Even though the limited sampling sites with single-visit procedures may affect the assessment results, our study provided important strategies for the development of multiple biological indices. Continual evaluation using longer term and larger data sets across different rivers will contribute to filling the knowledge gap.

Acknowledgements. This research was supported by the National Natural Science Foundation of China (No. 51208483, 51439007 and 51479219). The research also received financial support 
from the Project of State Key Laboratory of Simulation and Regulation of Water Cycle in River Basin (2014RC01). We extend sincere thanks to Dr Zhicai Xie, Junqian Zhang and Xiaoming Jiang, senior scientists at the Institute of Hydrobiology, Chinese Academy of Science, for their help in identification of rare species of macroinvertebrates and benthic diatoms.

\section{References}

Abell R.A., Olson D.M., Dinerstein E., Hurley P.T., Diggs J.T., Eichbaum W., Walters S., Wettengel W., Allnutt T., Loucks C.J. and Hedao P., 2000. Freshwater Ecoregions of North America, A conservation assessment. Island Press, Washington, DC.

Allan J.D. and Castillo M.M., 2007. Stream Ecology (2nd ed.), Springer-Verlag, New York.

Álvarez-Cabria M., Barquín J. and Juanes J.A., 2011. Macroinvertebrate community dynamics in a temperate European Atlantic river. Do they conform to general ecological theory? Hydrobiologia, 658, 277-291.

Arthington A.H., Bunn S.E., Poff N.L. and Naiman R.J., 2006. The challenge of providing environmental flow rules to sustain river ecosystems. Ecol. Appl., 16, 13111318.

Bae, M.-J., Kwon Y., Hwang S.-J., Chon T.-S., Yang H.-J., Kwak I.-S., Park J.-H., Ham S.-A. and Park Y.-S., 2011. Relationships between three major stream assemblages and their environmental factors in multiple spatial scales. Ann. Limnol.-Int. J. Limnol., 47, S91-S105.

Bae M.-J., Li F., Kwon Y.-S., Chung N., Choi H., Hwang S.-J. and Park Y.-S., 2014. Concordance of diatom, macroinvertebrate and fish assemblages in streams as nested spatial scales: implications for ecological integrity. Ecol. Indic., 47, 89-101.

Barbour M.T., Gerritsen J., Snyder B.D. and Stribling J.B., 1999. Rapid Bioassessment Protocols for use in Streams and Wadeable Rivers, Washington, US EPA 841B-99-002.

Boulton A.J., 1999. An overview of river health assessment: philosophies, practice, problems and prognosis. Freshwater Biol., 41, 469-479.

Bunn S.E., Abal E.G., Smith M.J., Choy S.C., Fellows C.S., Harch B.D., Kennard M.J. and Sheldon F., 2010. Integration of science and monitoring of river ecosystem health to guide investments in catchment protection and rehabilitation. Freshwater Biol., 55, 223-240.

Cairns J. Jr. and Pratt J.R., 1993. A history of biological monitoring using benthic macroinvertebrates. In: Rosenberg D.M. and Resh V.H. (eds) Freshwater Biomonitoring and Benthic Macroinvertebrates, Chapman \& Hall, London.

Chessman B.C. and Royal M.J., 2004. Bioassessment without reference sites: use of environmental filters to predict natural assemblages of river macroinvertebrates. J. N. Am. Benthol. Soc., 23, 599-615.

Clements W.H., Carlisle D.M., Lazorchak J.M. and Johnson P.C., 2000. Heavy metals structure benthic communities in Colorado Mountain streams. Ecol. Appl., 10, 626-638.

De Lange H.J., De Jonge J., Den Besten P.J., Oosterbaan J. and Peeters E.T.H.M., 2004. Sediment pollution and predation affect structure and production of benthic macroinvertebrate communities in the Rhine-Meuse delta, the Netherlands. J. N. Am. Benthol. Soc., 23, 557-579.

Dolédec S. and Statzner B., 2010. Responses of freshwater biota to human disturbances: contribution of J-NABS to developments in ecological integrity assessments. J. N. Am. Benthol. Soc., 29, 286-311.

Flinders C.A., Horwitz R.J. and Belton T., 2008. Relationship of fish and macroinvertebrate communities in the mid-Atlantic uplands: implications for integrated assessments. Ecol. Indic., 8, 588-598.

Geng S.W., Qu X.D., Zhang Y. and Lin K.D., 2012. Comparison and application of biological indices of macroinvertebrates in river health assessment. Environ. Sci., 33, 2281-2287 (in Chinese with English abstract).

Hawkins C.P., 2006. Quantifying biological integrity by taxonomic completeness: its utility in regional and global assessments. Ecol. Appl., 16, 1277-1294.

Hawkins C.P., Cao Y. and Roper B., 2010. Method of predicting reference condition biota affects the performance and interpretation of ecological indices. Freshwater Biol., 55, 1066-1085.

Hellawell J.M., 1986. Biological Indicators of Freshwater Pollution and Environmental Management, Elsevier, London, England.

Hering D., Meier C., Rawer-Jost C., Feld C.K., Biss R., Zenker A., Sundermann A., Lohse S. and Bohmer J., 2004. Assessing streams in Germany with benthic invertebrates: selection of candidate metrics. Limnologica, 34, $398-415$.

Hering D., Johnson R.K., Kramm S., Schmutz S., Szoszkiewicz K. and Verdonschot P.F.M., 2006. Assessment of European streams with diatoms, macrophytes, macroinvertebrates and fish: a comparative metric-based analysis of organism response to stress. Freshwater Biol., 51, 1757-1785.

Hering D., Borja A., Carstensen J., Carvalho L., Elliott M., Feld C.K., Heiskanen A.-S., Johnson R.K., Moe J., Pont D., Solheim A.L. and van de Bund W., 2010. The European Water Framework Directive at the age of 10: a critical review of the achievements with recommendations for the future. Sci. Total Environ., 408, 4007-4019.

Hilsenhoff W.L., 1988. Rapid field assessment of organic pollution with a family-level biotic index. J. N. Am. Benthol. Soc., 7, 65-68.

Hu H.J., Li R.Y., Wei Y.X., Zhu H.Z., Chen J.Y. and Shi Z.X., 1980. Freshwater Algae in China, Shanghai Science and Technology Press, Shanghai, China (in Chinese).

Hynes H.B.N., 1960. The Biology of Polluted Waters, Liverpool University Press, Liverpool, UK.

Karr J.R., 1981. Assessment of biotic integrity using fish communities. Fisheries, 6, 21-27.

Karr J.R., 1999. Defining and measuring river health. Freshwater Biol., 41, 221-234.

Karr J.R. and Chu E.W., 1999. Restoring life in running waters: better biological monitoring. Water Air Soil Poll., 116, 666-667.

Kennard M.J., Pusey B.J., Arthington A.H., Harch B.D., Mackay S.J., 2006. Development and application of a predictive model of freshwater fish assemblage composition to evaluate river health in eastern Australia. Hydrobiologia, $572,33-57$. 
Kerans B.L. and Karr J.R., 1994. A Benthic index of biotic integrity (B-IBI) for rivers of the Tennessee Valley. Ecol. Appl., 4, 768-785.

Kong W.J., Meng W., Zhang Y., Gipple C. and Qu X.D., 2013. A freshwater ecoregion delineation approach based on freshwater macroinvertebrate community features and spatial environmental data in Taizi River Basin, northeastern China. Ecol. Res., 28, 581-592.

Lecointe C., Coste M. and Prygiel J., 2003. OMNIDIA 3.2. Diatom index software including diatom database with taxonomic names, references and codes of 11645 diatom taxa.

Leigh C., Qu X., Zhang Y., Kong W., Meng W., Hanington P., Speed R., Gippel C., Bond N., Catford J., Bunn S. and Close P., 2012. Assessment of River Health in the Liao River Basin (Taizi Subcatchment), International Water Centre, Brisbane, Australia.

Magurran A.E., 2004. Measuring Biological Diversity, Blackwell Publishing, Oxford, UK.

Meng W., Zhang N., Zhang Y. and Zheng B.H., 2009. Integrated assessment of river health based on water quality, aquatic life and physical habitat. J. Environ. Sci., 21, 1017-1027.

Merritt R.W. and Cummins K.W., 1996. An Introduction to the Aquatic Insects of North America, Kendall/Hunt Publishing Company, Dubuque, USA.

Metcalfe J.L., 1989. Biological water quality assessment of running waters based on macroinvertebrate communities: history and present status in Europe. Environ. Poll., 60, 101-139.

Millennium Ecosystem Assessment, 2005. Ecosystems and Human Well-Being: Synthesis, Island Press, Washington, DC.

Ministry of Environmental Protection, 2009. Chinese Standard Methods for Examination of Water and Wastewater (4th ed.), Chinese Environmental Science Press, Beijing, China (In Chinese).

Morse J.C., Yang L.F. and Tian L.X., 1994. Aquatic Insects of China Useful for Monitoring Water Quality, Hohai University Press, China.

Norris R.H. and Hawkins C.P., 2000. Monitoring river health. Hydrobiologia, 435, 5-17.

Park Y.S., Song M.Y., Park Y.C., Oh K.H., Cho E. and Chon T.S., 2007. Community patterns of benthic macroinvertebrates collected on the national scale in Korea. Ecol. Model., 203, 26-33.

Plafkin J.L., Barbour M.T., Porter K.D., Gross S.K. and Hughes R.M., 1989. Rapid Bioassessment Protocols for Use in Streams and Rivers: Benthic Macroinvertebrates and Fish. EPA 440-4-89-001, Office of Water Regulations and Standards, US Environmental Protection Agency, Washington, DC.

Prygiel J., Rosso-Darmet A., Lafont M., Lesniak C., Durbec A. and Ouddane B., 1999. Use of Oligochaete communities for assessment of ecotoxicological risk in fine sediment of rivers and canals of the Artois-Picardie water basin (France). Hydrobiologia, 410, 25-37.

Qu X.D., Wu N.C., Tang T., Cai Q.H. and Park Y.S., 2010. Effects of heavy metals on benthic macroinvertebrate communities in high mountain streams. Ann. Limnol. - Int. J. Limnol., 46, 291-302.

Qu X.D., Liu Z.G. and Zhang Y., 2012. Discussion on the standardized method of reference sites selection for establishing the Benthic-Index of Biotic Integrity. Acta Ecol. Sin., 15, 4661-4672.

Qu X.D., Zhang Y., Ma S.Q., Zhao R. and Meng W., 2013. Spatial distribution characteristics of macroinvertebrate communities in Taizi River basin. Res. Environ. Sci., 26, 509-515 (in Chinese with English abstract).

Qu X.D., Zhou Y., Zhao R., Bentsen C., Yin X.W. and Zhang Y., 2014. Are Diatom-based indices from Europe suitable for river health assessment in China? A case study from Taizi River, Northeastern China. Br. J. Environ. Climate Change, 4, 95-114.

Rabeni C.F., Doisy K.E. and Zweig L.D., 2005. Stream invertebrate community functional responses to deposited sediment. Aquat. Sci., 67, 395-402.

Resh V.H., 2008. Which group is best? Attributes of different biological assemblages used in freshwater biomonitoring programs. Environ. Monit. Assess., 138, 131-138.

Reynoldson T.B., Norris R.H., Resh V.H., Day K.E. and Rosenberg D.M., 1997. The reference condition: a comparison of multimetric and multivariate approaches to assess water-quality impairment using benthic macroinvertebrates. J. N. Am. Benthol. Soc., 16, 833-852.

Rosenberg D.M. and Resh V.H., 1993. Freshwater Biomonitoring and Benthic Macroinvertebrates, Chapman \& Hall, London.

Stevenson R.J. and Pan T.D., 1999. Assessing environmental conditions in rivers and streams with diatoms. In: Stoermer E.F. and Smol J.P. (eds) The Diatoms: Applications for the Environmental and Earth Sciences, Cambridge University Press, Cambridge, pp. 11-40.

Stoddard J.L., Larsen D.P., Hawkins C.P., Johnson R.K. and Norris R.H., 2006. Setting expectations for the ecological condition of streams: the concept of reference condition. Ecol. Appl., 16, 1267-1276.

Stribling J.B., Jessup B.K. and Gerritsen J., 1999. Development of biological and habitat criteria for Wyoming streams and their use in the TMDL process, prepared by Tetra Tech, Inc., Owings Mills, MD, for U.S. EPA, Region 8, Denver, CO.

Vannote R.L., Minshall G.W., Cummins K.W., Sedell J.R. and Cushing C.E., 1980. The river continuum concept. Can. J. Fish. Aquat. Sci., 37, 130-137.

Wang W., Wang B., He X.Y., Qu X.D. and Zhang Y., 2013. Study of zoning and distribution characteristics of fish in Taizi River. Res. Environ. Sci., 26, 494-501 (in Chinese with English abstract).

Wu N.C., Tang T., Zhou S.C., Jia X.H., Li D.F., Liu R.Q. and Cai Q.H., 2009. Changes in benthic algae communities following construction of a run-of-river dam. J. N. Am. Benthol. Soc., 28, 69-79.

Xie Y., 2007. Freshwater Fishes in Northwest Region of China, Liaoning Science and Technology Press, Shenyang, China (in Chinese).

Yin X.W., Zhang Y., Qu X.D. and Meng W., 2013. Spatial community structure of periphyton assemblages in the Taizihe River basin. Res. Environ. Sci., 26, 502-508. (in Chinese with English abstract).

Zhang J.M., 1995. The Ichthyography of Heilongjiang River, Heilongjiang Science and Technology Press, Haierbin, China (in Chinese).

Zhang N., Meng W., Zhang Y. and Zheng B.H., 2009. Multivariable assessment of river ecosystem health in Liao River 
basin. Res. Environ. Sci., 22, 162-170 (in Chinese with English abstract).

Zhang Y., Zhao R., Qu X.D. and Meng W., 2013. The researches of integrated river health assessment of Liaohe River basin. Eng. Sci., 15, 11-18 (in Chinese with English abstract).
Zheng W.H., Qu X.D., Zhang Y. and Meng W., 2011. Habitat suitability of macroinvertebrates in the Taizi River basin, northeast China. Res. Environ. Sci., 24, 1355-1363. (in Chinese with English abstract).

Zhu H.Z. and Chen J.Y., 2000. Bacillariophyta of the Xizang Plateau, Science Press, Beijing, China (in Chinese). 